\title{
First Breast Cancer Treatment Naturally by Nanoskin Act
}

\author{
Pierre Basmaji \\ Innovatecs Biotechnology Research Center, Sao Carlos, Brazil \\ Email: nanoskin.healing@gmail.com
}

How to cite this paper: Basmaji, P. (2020) First Breast Cancer Treatment Naturally by Nanoskin Act. Journal of Biomaterials and Nanobiotechnology, 11, 179-187. https://doi.org/10.4236/jbnb.2020.113011

Received: March 31, 2020

Accepted: May 30, 2020

Published: June 2, 2020

Copyright $\odot 2020$ by author(s) and Scientific Research Publishing Inc. This work is licensed under the Creative Commons Attribution International License (CC BY 4.0).

http://creativecommons.org/licenses/by/4.0/

\begin{abstract}
It's well known that the cancer cell has tendency to grow fast. Chemotherapy drugs have been used in order to kill cancer growing cells and take immune system weakly. However, side effect can damage these healthy cells. Moreover, it is not natural treatment. Natural alternative cancer treatments may be able to help and open new way for cancer treatment. In this work, we transfer cancer nodule to wound and we treat the nodule as wound, using Nanoskin ${ }^{\circ}$ advance cell therapy (ACT), natural extra cellular matrix which releases oxygen to the cancer tissue. Our result shows that the cancer nodule becomes like chronic wound opened and then disappeared. In addition, we obtained complete healing wound.
\end{abstract}

\section{Keywords}

Nanoskin ACT Bacterial Cellulose, Natural Membrane, Breast Cancer, Wound Healing, Tissue Regeneration

\section{Introduction}

Tumoral wounds, malignant wounds, fungoid lesions or ulcerating wounds occur due to the breaking of the integrity of the skin, resulting from uncontrolled cellular proliferation with consequent infiltration of malignant cells into the structures of the skin [1].

The optimal skin substitute will provide for immediate replacement of both the lost dermis and epidermis, with permanent wound coverage.

Oxygen is a necessary component of normal wound healing and is required for multiple cell functions, including the killing of bacteria by leukocytes. However, the $\mathrm{pH}$ of the wound can affect many factors including oxygen release, angiogenesis, protease activity, and bacterial toxicity. Chronic non-healing wounds have an elevated alkaline environment. Healing occurs more readily in an acid 
environment. In addition to the effects on protease activity and oxygen release, other effects of lowering the $\mathrm{pH}$ to a more acidic environment are to reduce the toxicity of bacterial end products such as ammonia, enhancing the destruction of abnormal collagen in the ulcer bed, promotion of angiogenesis, increased macrophage and fibroblast activity and control of enzyme activity.

Nanoskin ${ }^{\circledR}$ ACT natural extra cellular matrix bacterial cellulose (ECM-BC) release oxygen to the tissue is fiber polysaccharides can significantly promote DNA synthesis and increase cell division, thus delaying the aging body. These fibers are of high concentration of flavonoid compounds, diterpene, triterpene, lignans, phenylpropanoids and prenylated acetophenones to strengthen our immunity cells and improve our immune system, moreover, contain substances such as $\beta$-glucan polysaccharide and significant amount of glucuronic acid, which acts physiologically in the body as an effective detoxifying agent.

Nanoskin ${ }^{\circledast}$ ACT Bacterial cellulose (BC) has been already reported in ref s [2] [3] [4] [5]. The structural features of microbial cellulose, its properties and compatibility as a biomaterial for regenerative medicine can be changed by modifying its culture medium ref [6] or surface modification by physical ref s [7] [8]; chemical methods and genetic modifications ref [9] to obtain a biomaterial with less rejection when in contact to the body.

ECM synthesis and new vessels, granulation tissue formation and epithelialization by Keratinocyte migration, result in an increase in the dermis volume and accelerate the healing ref's [10] [11]. However, structural changes may interfere with the physical chemical properties of the surface, producing a biomaterial with properties like tissue/implant interface stability suitable for cell adhesion. Besides, recent works study chemical changes in bacterial cellulose surface for tissue engineering and regenerative medicine ref's [12] [13] [14] [15] [16].

In this work, novel studies of natural nanocomposites with NANOSKIN ACT bacterial cellulose for functional materials are reported with complete breast cancer wound healing. In order to produce scaffolds with drug delivery ability and better cell adhesion, fermentation changes in bacterial cellulose with chondroitin sulfate, hyaluronicacid and beta glucan.

$\beta$-glucans is are polysaccharides that constitute the structure of the cell wall of yeast, fungi and some cereals, which differs each other by the linkages between glucose units. The $\beta$-glucan is considered to be a modifier of biological response due to its immunomodulator potential. When it is recognized by specific cellular receptors, have the ability to enhance the host's immune response. Other beneficial effects such as anticarcinogenic, antimutagenic, hypocholesterolemic and blood sugar reduction have also been related to the $\beta$-glucan.

\section{Materials and Methods}

\subsection{Materials}

The bacterial cellulose-Nanoskin ${ }^{\circledast}$ ACT raw material was provided from Innovatec's (Sao Carlos SP, Brazil). Chondroitin sulfate, hyaluronic acid and beta glu- 
can were purchased from Sigma Aldrich.

\subsection{Methods}

Synthesis of Bacterial Cellulose and Bacterial Cellulose/Chondroitin Sulfate/Hyaluronic Acid/Beta-Glucan

The acetic fermentation process was achieved by using glucose as a carbohydrate source. Results of this process are vinegar and a nanobiocellulose biomass. The modifying process is based on the addition of hyaluronic acid, chondroitin sulfate and beta-glucan $(1 \% \mathrm{w} / \mathrm{w})$ to the culture medium before the bacteria is inoculated.

Bacterial cellulose (BC) is produced by Gram-negative bacteria Gluconacetobacter xylinus, which can be obtained from the culture medium in the pure 3-D structure, consisting of an ultra fine network of cellulose nanofibers ref [11].

\subsection{Characterization}

$\beta$-glucans is are polysaccharides that constitute the structure of the cell wall of yeast, fungi and some cereals, which differs each other by the linkages between glucose units. The $\beta$-glucan is considered to be a modifier of biological response due to its immunomodulator potential. When it is recognized by specific cellular receptors, have the ability to enhance the host's immune response. Other beneficial effects such as anticarcinogenic, antimutagenic, hypocholesterolemic and blood sugar reduction have also been related to the $\beta$-glucan. Figure 1 shows NANOPARTICLE OF $\beta$-glucan low molecule weight. Figure 2 shows the nano $\beta$-glucan formation.

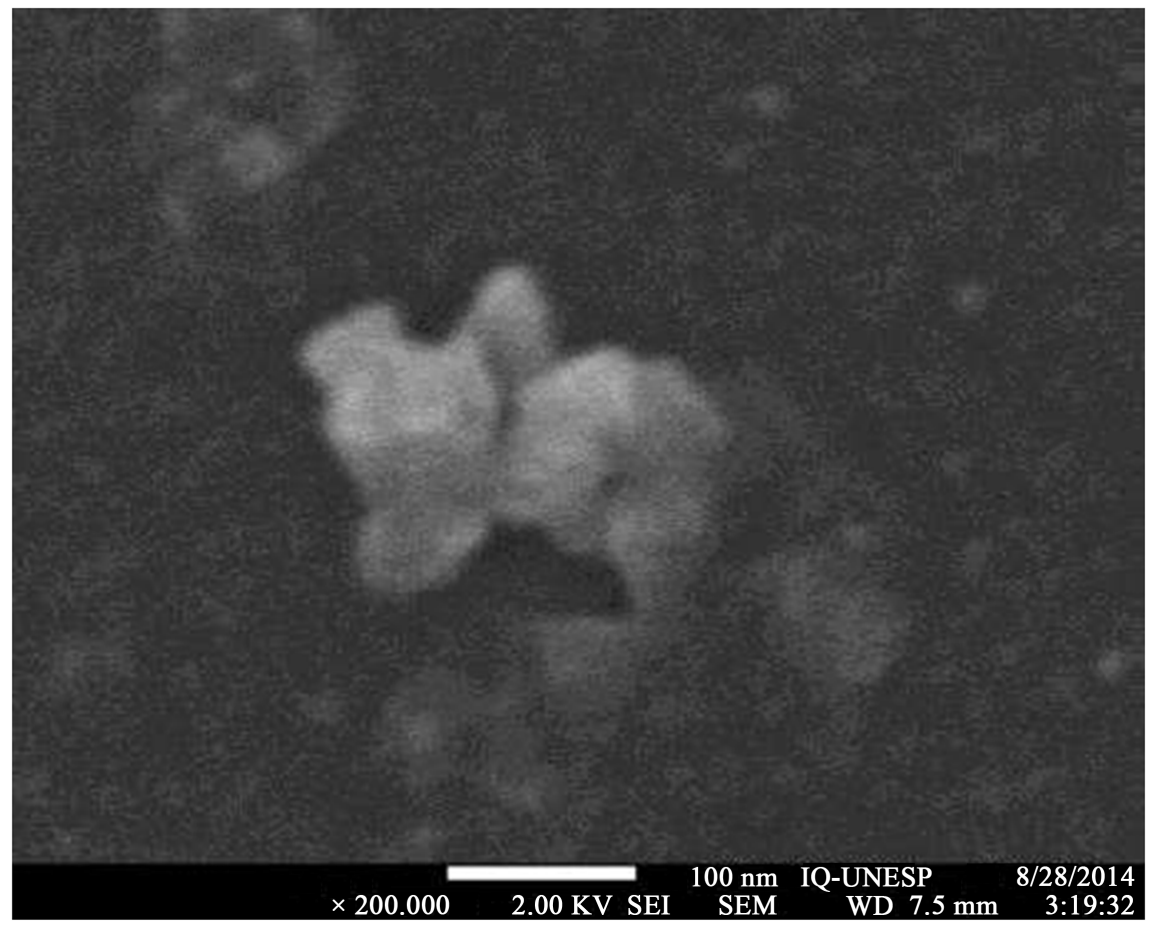

Figure 1. Nanoparticle of $\beta$-glucan low molecule weight. 


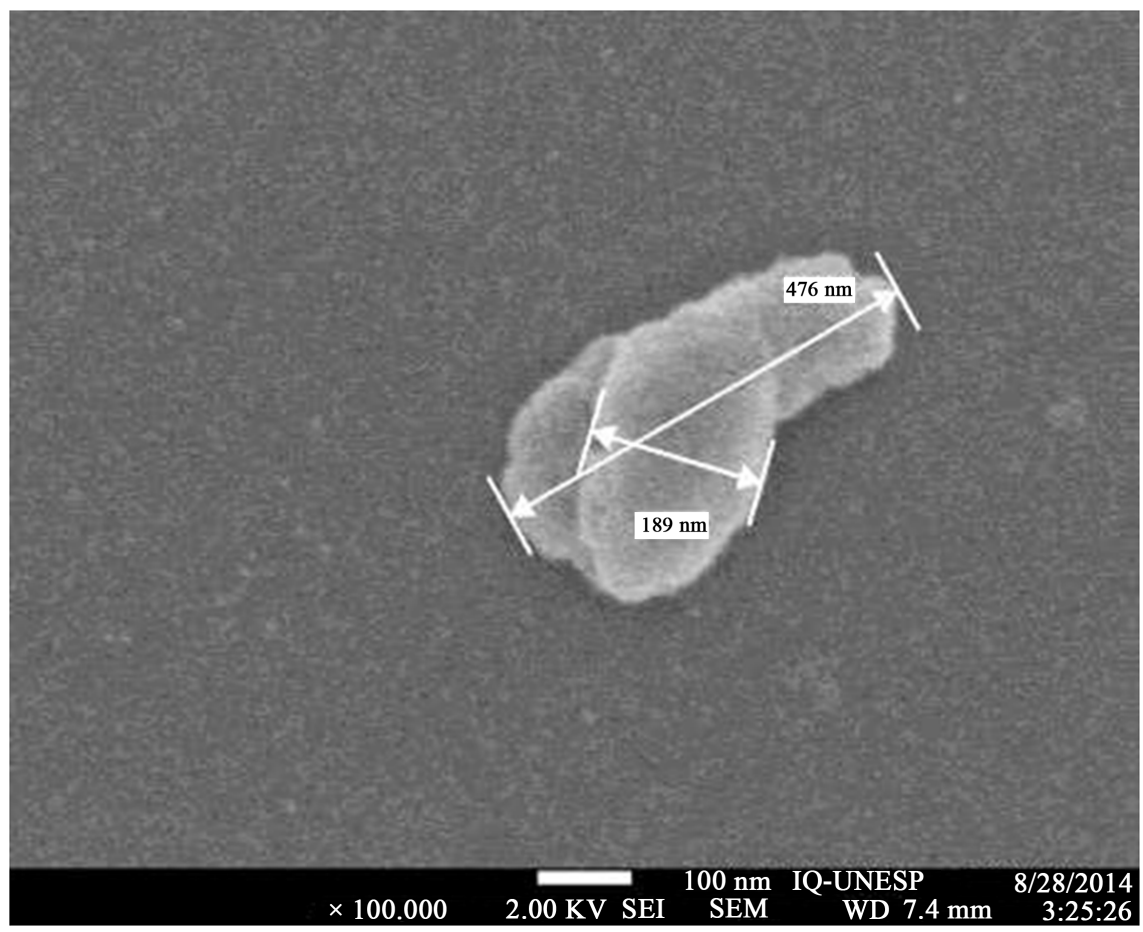

Figure 2. Shows microscopic image of $\beta$-glucan.

The antimicrobial activity of these peptides depends on the ionic conditions of exudates released by the body, for its main mechanism of action grounded in this initial interaction of its cationic residues with anionic groups present in phospholipids microbial wrap or reactivity with products protein excreted by the microbes, which promote processing the substrates of the environment as similable nutrients.

The hollow structure of particulate $\beta$-glucan has recently been harnessed to utilize particulate $\beta$-glucan as a delivery vesicle. These new concepts, along with the emerging success of combinatorial approaches to cancer treatment involving $\beta$-glucan, suggest that $\beta$-glucan may play an essential role in future strategies to prevent and inhibit tumor growth.

\subsection{In Vivo Analysis Nanoskin ${ }^{\circledR}$ ACT}

\section{Case I}

\section{History}

"In 2015 I discovered a lump breast, I had a biopsy and a carcinoma was found. I took it to the doctor who said he would have to start treatment immediately, as the lump was already about two centimeters. However, as it never crossed my mind to have something like this, much less do the traditional treatment which is chemotherapy, removing the breast, radiotherapy. So I went in search of another treatment. That was when my niece, who lives in Brasília, appointed me Dr Pierre at INNOVATECS research center. During our consultation, he instructed me to change my diet and use natural medicines. However, at that moment the nodule had already grown a little longer, it was already about 
six centimeters. There was a possibility of metastasis in the liver and bone. I stayed firm and the treatment started to work out, the nodule gradually regressed until it disappeared". We decide to transfer the nodule to wound then we can treat it as chronic wound using Nanoskin ACT. We start treatment on September 2016 by applying special Nanoskin ACT membrane. In Figure 3, we can see the nodule position.

We start treatment applying Nanoskin ACT with interval time changing every $48 \mathrm{~h}$. During this period, patient maintains especial nutrition, antioxidant Elixir adaptogens, semiotics based in Nanoskin fibers in order to enhance her immunological system (Figure 4).

After 10 months, the nodule start to have wound aspect and some liquid start go out as we can see in the Figure 5.

And after 2 years of treatment with Nanoskin ACT membrane, the nodule has disappeared and we obtained complete healing. Figure 6 shows the complete healing.

Lady health life has been monitoring during 2 years until this date. Our patient has excellent life and no more signal of any tumor cell in her body.

\section{Case II}

Another case of maxillary cancer has been also treated successfully with $\mathrm{Na}$ noskin ACT, as we can see in Figure 7.

\section{Case III}

Another case of palate cancer has been treated with the some way using $\mathrm{Na}$ noskin ACT membrane, results can be seen in Figure 8.

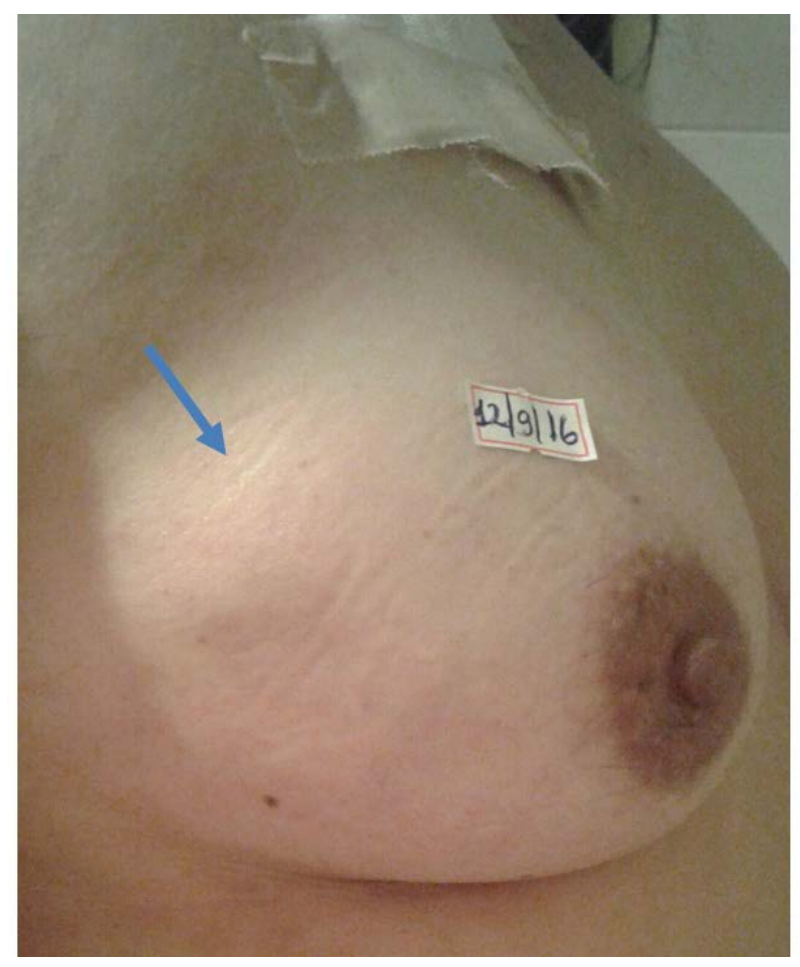

Figure 3. Nodule position. 


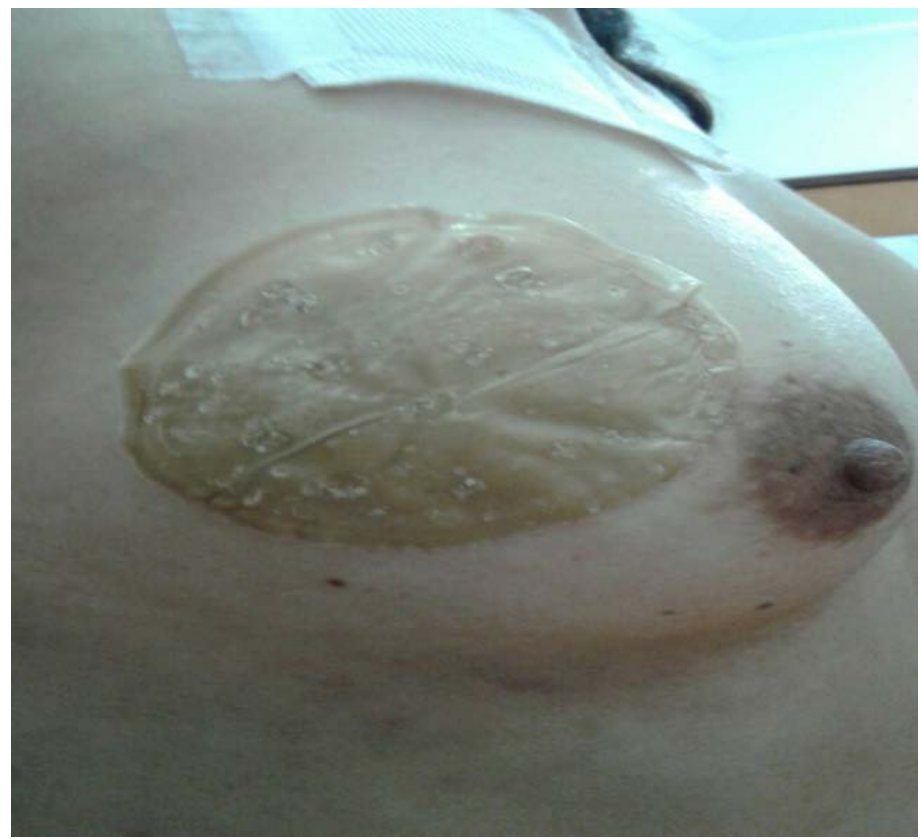

Figure 4. Shows how apply Nanoskin ACT to nodule.

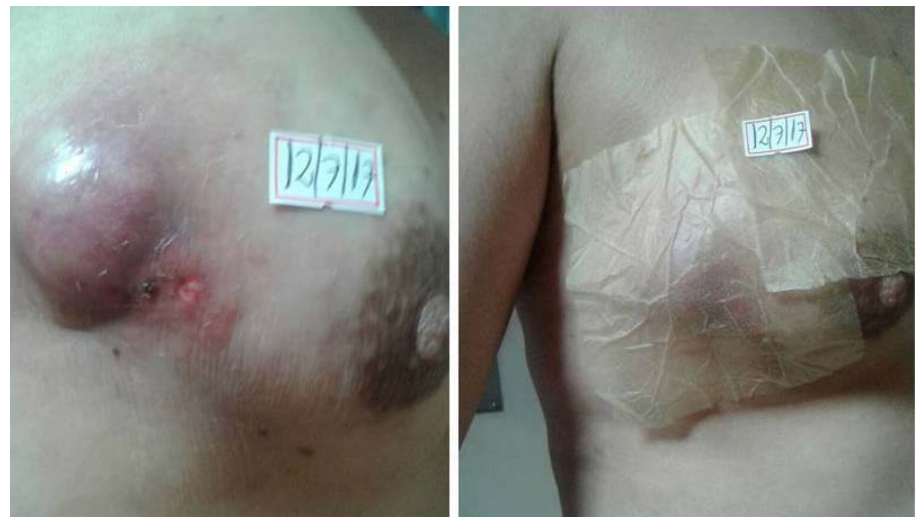

Figure 5. Nodule starts to deliver exudates.

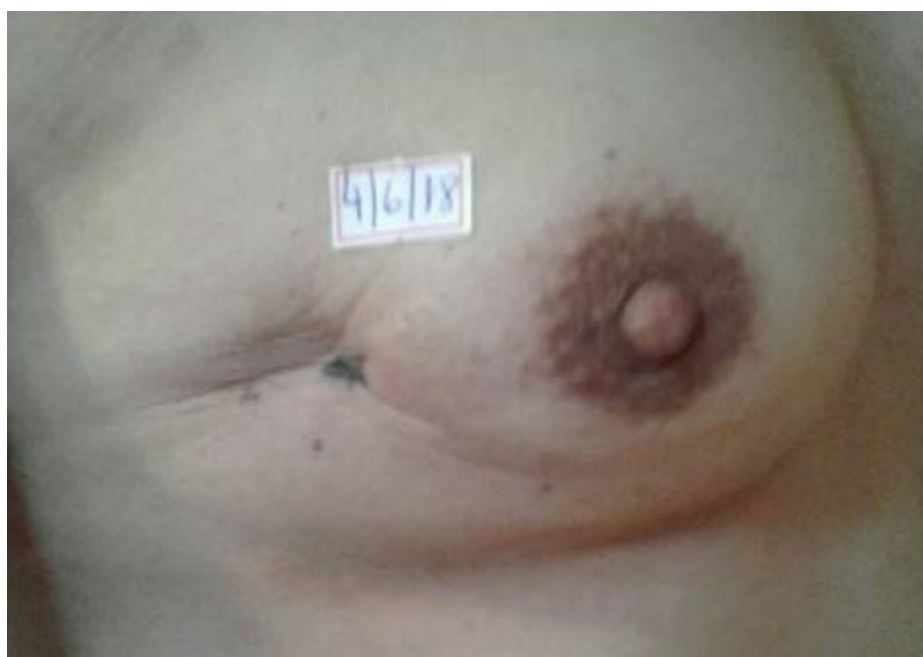

Figure 6. Complete healing of Breast cancer. 


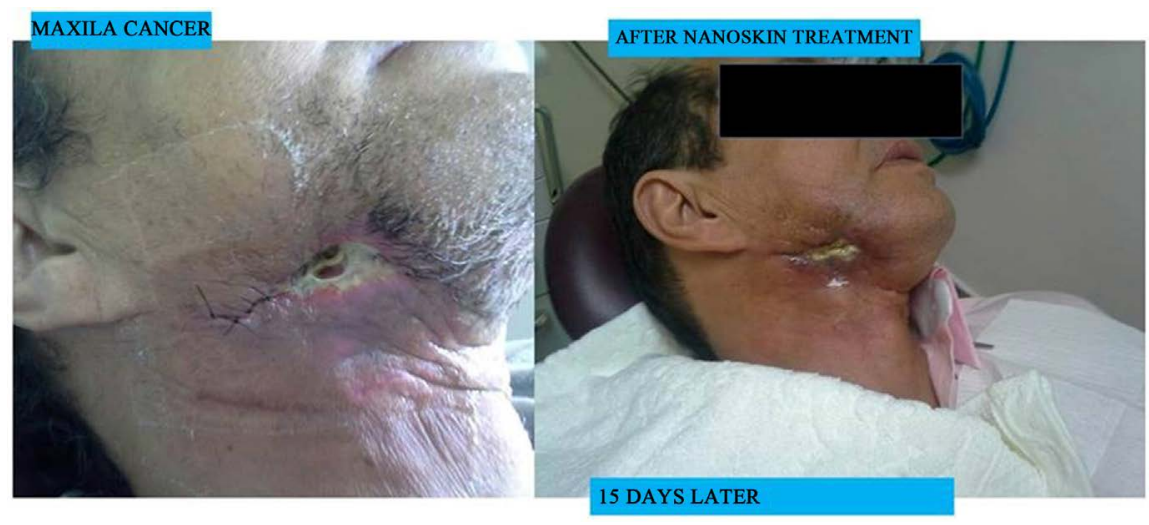

Figure 7. Maxillary cancer treated by Nanoskin ACT.

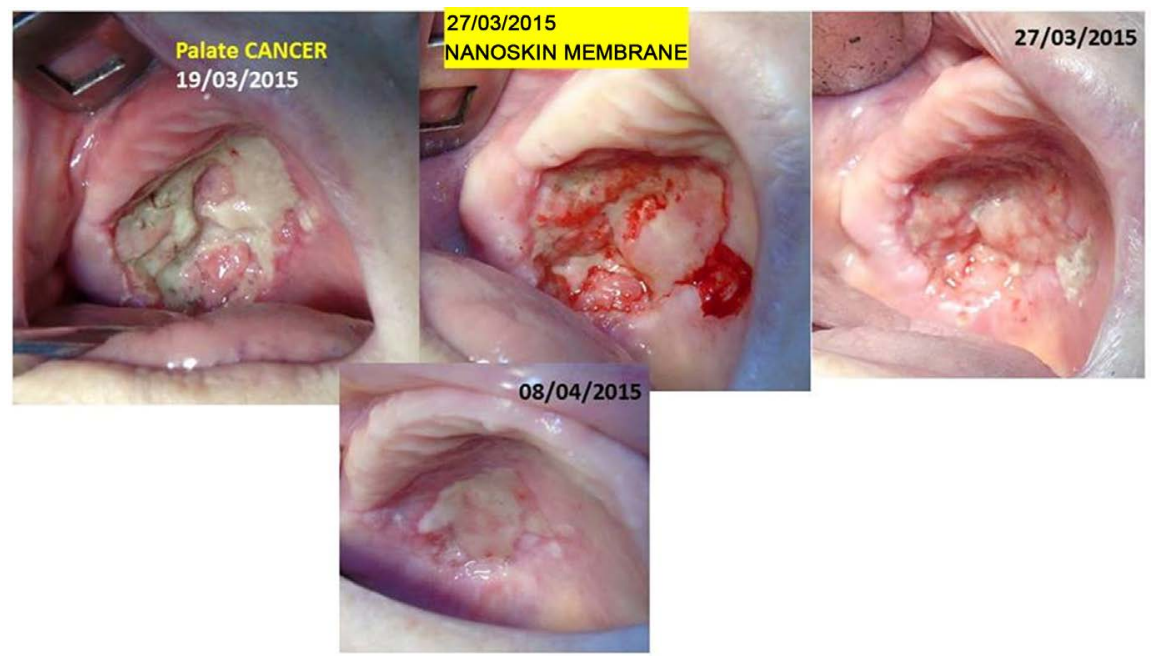

Figure 8. Palate cancer treated by Nanoskin ACT membrane.

\section{Conclusions}

We report the first successful case of breast cancer treated by Nanoskin ACT.

Our results open a new way for no invasive naturally treatment without side effect of chemotherapy or radiation.

\section{Acknowledgements}

The author would like to thank to the Multipurpose Gamma Irradiation Facility-CETER/IPEN.

\section{Conflicts of Interest}

The author declares no conflicts of interest regarding the publication of this paper.

\section{References}

[1] Ministério da Saúde (Brasil). Instituto Nacional do Câncer-INCA (2009) Tratamento e controle de feridas tumorais e úlceras por pressão no câncer avançado. MS. Série Cuidados Paliativos, Rio de Janeiro. 
[2] Olyveira, G.M., Costa, L.M.M., Riccardi, C.S., Santos, M.L., Daltro, P.B., Basmaji, P., Daltro, G.C. and Guastaldi, A.C. (2016) Bacterial Cellulose for Advanced Medical Materials. In: Grumezescu, A.M., Ed., Nanobiomaterials in Soft Tissue Engineering, Elsevier, Romania, 57-82. https://doi.org/10.1016/B978-0-323-42865-1.00003-9

[3] Olyveira, G.M., Santos, M.L., Riccardi, C.S., Costa, L.M.M., Daltro, P.B., Basmaji, P., Daltro, G.C. and Guastaldi, A.C. (2015) Bacterial Cellulose Biocomposites for Periodontology Treatment. Advanced Science. Engineering and Medicine, 7, 409-414. https://doi.org/10.1166/asem.2015.1641

[4] Filho, L.X., OLyveira, G.M., Costa, L.M.M. and Basmaji, P. (2013) Novel Electrospun Nanotholits/PHB Scaffolds for Bone Tissue Regeneration. Journal of Nanoscience and Nanotechnology, 13, 4715-4719. https://doi.org/10.1166/jnn.2013.7191

[5] Basmaji, P., Ambrizzi, D.R., Olyveira, G.M., Costa, L.M.M., Francozo, G.B. and Oliveira, J.D.C. (2016) Natural Extracellular Matrix Modified for Tissue Engineering Applications. Advanced Science, Engineering and Medicine, 8, 62-67. https://doi.org/10.1166/asem.2016.1817

[6] Costa, L.M.M., Olyveira, G.M., Basmaji, P. and Filho, L.X. (2011) Bacterial Cellulose towards Functional Green Composites Materials. Journal of Bionanoscience, 5, 167-172. https://doi.org/10.1166/jbns.2011.1060

[7] Costa, L.M.M., Olyveira, G.M., Basmaji, P. and Filho, L.X. (2012) Bacterial Cellulose towards Functional Medical Materials. Journal of Biomaterials and Tissue Engineering, 2, 185-196. https://doi.org/10.1166/jbt.2012.1044

[8] Olyveira, G.M., Costa, L.M.M. and Basmaji, P. (2013) Physically Modified Bacterial Cellulose as Alternative Routes for Transdermal Drug Delivery. Journal of Biomaterials and Tissue Engineering, 3, 227-232. https://doi.org/10.1166/jbt.2013.1079

[9] Olyveira, G.M., Riccardi, C.S., Santos, M.L., Costa, L.M.M., Daltro, P.B., Basmaji, P., Daltro, G.C. and Guastaldi, A.C. (2014) Bacterial Cellulose Nanobiocomposites for Periodontal Disease. Journal of Bionanoscience, 8, 319-324. https://doi.org/10.1166/jbns.2014.1241

[10] Basmaji, P., Olyveira, G.M. and Costa, L.M.M. (2015) Nanoskin Extracellular Matrix Modified with Hyaluronic Acid and Chondroitin Sulfate for Regenerative Medicine Applications. Journal of Bionanoscience, 9, 306-310. https://doi.org/10.1166/jbns.2015.1304

[11] Olyveira, G.M., Santos, M.L., Daltro, P.B., Basmaji, P., Daltro, G.C. and Guastaldi, A.C. (2014) Bacterial Cellulose/Chondroitin Sulfate for Dental Materials Scaffolds. Journal of Biomaterials and Tissue Engineering, 4, 150-154. https://doi.org/10.1166/jbt.2014.1155

[12] Olyveira, G.M., Santos, M.L., Costa, L.M.M., Daltro, P.B., Basmaji, P., Daltro, G.C. and Guastaldi, A.C. (2014) Bacterial Cellulose Nanobiocomposites for Dental Materials Scaffolds. Journal of Biomaterials and Tissue Engineering, 4, 536-542. https://doi.org/10.4236/jbnb.2018.91007

[13] Olyveira, G.M., Santos, M.L., Costa, L.M.M., Daltro, P.B., Basmaji, P., Daltro, G.C. and Guastaldi, A.C. (2014) Bacterial Biocomposites for Guided Tissue Regeneration. Science of Advanced Materials, 6, 2673-2678.

https://doi.org/10.1166/sam.2014.1985

[14] Olyveira, G.M., Santos, M.L., Costa, L.M.M., Daltro, P.B., Basmaji, P., Daltro, G.C. and Guastaldi, A.C. (2015) Physically Modified Bacterial Cellulose Biocomposites for Guided Tissue Regeneration. Science of Advanced Materials, 7, 1657-1664. https://doi.org/10.1166/sam.2015.2283

[15] Olyveira, G.M., Basmaji, P., Costa, L.M.M., Santos, M.L., Riccardi, C.S., Guastaldi, 
F.P.S., Scarel-Caminaga, R.M., Oliveira Capote, T.S., Pizoni, E. and Guastaldi, A.C. (2017) Surface Physical Chemistry Properties in Coated Bacterial Cellulose Membranes with Calcium Phosphate. Materials Science \& Engineering. C, Materials for Biological Applications, 75, 1359-1365. https://doi.org/10.1016/j.msec.2017.03.025

[16] Olyveira, G.M., Chanfrau, J.E.R., Costa, L.M.M., Basmaji, P., Ambrozini, B., Pizoni, E. and Guastaldi, A.C. (2017) Physical Chemistry Properties Influences in Bacterial Cellulose Biocomposites. Journal of Bionanoscience, 11, 573-577.

https://doi.org/10.1166/jbns.2017.1477 